medical research achievements and clinical guidelines, will play an important role in advancing further the treatment of substance use disorder.

\section{References}

Adamson S. J., Heather N., Morton V., et al (2010) Initial preference for drinking goal in the treatment of alcohol problems: II. Treatment outcomes. Alcohol and Alcoholism, 45, 136-142.

European Commission (2017) Mental Health: How Many Psychiatrists in the EU? Eurostat. Available at: http://ec.europa.eu/eurostat/web/ products-eurostat-news/-/EDN-20171010-1?inheritRedirect=true (accessed 25 March 2018)

European Monitoring Centre for Drugs and Drug Addiction (2015) The European School Survey Project on Alcohol and other Drugs. Available at: http://www.espad.org/report/country-summaries\#cyprus (accessed 25 March 2018).

European Monitoring Centre for Drugs and Drug Addiction (2017) Cyprus Country Drug Report 2017. Available at: http://www.emcdda. europa.eu/publications/country-drug-reports/2017/cyprus_en (accessed 25 March 2018).

European Monitoring Centre for Drugs and Drug Addiction (2018) Wastewater Analysis and Drugs, a European Multi-City Study. Available at: http://www.emcdda.europa.eu/system/files/publications/ 2757/POD_Wastewater\%20analysis.pdf (accessed 25 March 2018).
Heather N., Adamson S. J., Raistrick D., et al (2010) Initial preference for drinking goal in the treatment of alcohol problems: I. Baseline differences between abstinence and non-abstinence groups. Alcohol and Alcoholism, 45, 128-135.

House of Representatives, Health Committee, Pending Commission Regulations (2018) Available at: http://www2.parliament.cy/ parliamentgr/008_07.htm (accessed 25 March 2018).

Kourounis G., Richards B. D. W., Kyprianou E., et al (2016) Opioid substitution therapy: lowering the treatment thresholds. Drug and Alcohol Dependence, 161, 1-8.

Ministry of Health, Cyprus (2018) Smoking Cessation Programs. Ministry of Health. Available at: https://www.moh.gov.cy/Moh/MOH. nsf/All/4DE89017D625FCF042257997003A4C42?OpenDocument (accessed 25 March 2018).

National Institute for Health and Care Excellence (NICE) (2011) Alcohol-Use Disorders: Diagnosis, Assessment and Management of Harmful Drinking and Alcohol Dependence. NICE. Available at: https:// www.nice.org.uk/guidance/cg115 (accessed 25 March 2018).

Prodromou M., Kyritsi E. \& Samartzis L. (2014) Dual diagnosis affects prognosis in patients with drug dependence in integrative care setting. Health Science Journal, 8, 216-228.

Taylor D., Paton C. \& Kapur S. (2015) The Maudsley Prescribing Guidelines in Psychiatry. John Wiley \& Sons.

\title{
MENTAL HEALTH LAW PROFILES \\ Mental health law in the Former Yugoslav Republic of Macedonia
}

\author{
Antoni Novotni, ${ }^{1}$ Nensi Manusheva ${ }^{1}$ and Gabriela Novotni ${ }^{2}$
}

${ }^{1}$ University Psychiatry Clinic, Skopje, Former Yugoslav Republic of Macedonia; email prof. novotni@gmail.com

${ }^{2}$ University Neurology Clinic, Skopje, Former Yugoslav Republic of Macedonia

\section{Conflict of interest: None.}

doi:10.1192/bji.2017.18

(C) The Authors 2018. This is an Open Access article, distributed under the terms of the Creative Commons Attribution-

NonCommerical-NoDerivatives licence (http://creativecommons. org/licenses/by-nc-nd/4.0/), which permits non-commercial re-use distribution, and reproduction in any medium, provided the original work is unaltered and is properly cited. The written permission of Cambridge University Press must be obtained for com Press must be obtained for commercial re use or in order to create a derivative work.
Psychiatrists are often confronted with the problem of non-consensual treatment. This paper focuses on the rights of patients with mental health disorders in the Former Yugoslav Republic of Macedonia in relation to non-consensual treatment and deprivation of liberty. The current mental health legislation and its implementation in local services is described with an emphasis on the assessment and treatment of patients with mental disorders.

\section{Mental health reforms in Former Yugoslav Republic of Macedonia}

Following its declaration of independence in 1991, the Former Yugoslav Republic (FYR) of Macedonia has adopted an extensive set of legal reforms. Several international legislative documents have been signed and ratified including the Convention Against Torture and Other Cruel, Inhuman or Degrading Treatment or Punishment (Law on Mental Health, 2006).

The FYR of Macedonia Parliament signed up to the National Mental Health Policy on 13
October 2005 (Law on Mental Health, 2006). The Policy includes the following components: developing community mental health services, downsizing large mental health hospitals, developing a mental health component in primary healthcare, development of human resources, involvement of patients and families, advocacy and promotion, human rights protection of patients, equity of access to mental health services across different groups, financing, quality improvement and monitoring systems.

This Policy also addresses and regulates issues such as access to mental healthcare, including the access to the least-restrictive care; rights of mental health service consumers, family members and caregivers; competency, capacity and guardianship issues for people with mental illness; voluntary and involuntary treatment; accreditation of facilities; law enforcement and other judicial system issues for people with mental illness; and mechanisms aimed at overseeing involuntary admission and associated treatment practices. However, there are still no mechanisms enabling the implementation of this Policy and, in practice, the implementation of new guidelines has been very slow.

Regular inspections and complaints processes are reviewed by a national human rights review 
body. Although $75 \%$ of mental hospitals have at least one review/inspection of human rights protection of patients per year, only $31 \%$ of community-based in-patient psychiatric units have such a review.

However, the National Program for the Treatment of People with Mental Disorders (WHO, 2009) offers improvements by decentralising mental healthcare to community mental care centres, which are distributed in various parts of the country. Currently there are eight such centres working on the re-socialisation and reintegration of people with mental disorders into society (Apostolska et al, 2009). Additional mental health legislation includes an important amendment (Law on Amendment and Addenda to the Law on the Protection of Patients' Rights, 2011) - the Supplement to the Law on Health Protection that helped to establish new institutions called 'Community Mental Health Centres' (CMHCs), which form part their public mental health services. These CMHCs have the role of organising and implementing treatment for people with a range of mental health problems with the aim of promoting mental health and preventing mental illnesses, providing psychosocial care and rehabilitation and reintegrating people with mental illnesses into the community.

The National Strategy for Mental Health 2014-2020 is in the final phase of preparation, as is the National Mental Health Action Plan. Its content is currently being debated by the National Mental Health Committee.

\section{Forensic and other residential facilities}

There are 123 beds in the mental hospitals for those in the criminal justice system. The period of hospitalisation for the general population of people with mental health disorders varies: $32 \%$ of patients are hospitalised for less than 1 year, $39 \%$ for $1-4$ years, $12 \%$ for $5-10$ years and $17 \%$ for more than 10 years. There are 477 beds for people with general mental disorders in other residential facilities.

\section{Hospitalisation can be voluntary or involuntary}

Of all admissions to mental hospitals, $4 \%$ are involuntary. Between $2-5 \%$ of patients were restrained or secluded at least once within the past year (2013) in mental hospitals.

According to the Law on Non-Litigation Procedures (Non-Litigation Law, 2008), when a person is voluntarily admitted they should submit a statement written in front of two adult witnesses who are not employed in the same public health institution and are not relatives of the person being hospitalised. People who are involuntarily hospitalised are accommodated in acute emergency units in conjunction with the relevant city's magistrates' court, which is empowered to make decisions regarding involuntary hospitalisations. Article 59 of the Law on Non-Litigation Procedures (Non-Litigation Law,
2008) stipulates that "When the health organization admits a mentally ill person without their consent or without a Court decision, the relevant person representing the public health institution is obliged to submit a report to the Court within 48 hours'. Furthermore, article 65 stipulates that 'The Court is obliged to establish the facts leading to a decision for an involuntary admission including a statement from the person subjected to such an admission, ensuring that an involuntary admission is not detrimental to their health'.

The policies regarding restraint in psychiatric hospitals are governed by relevant special protocols where policy is elaborated upon and the rules for appropriate restraint measures are detailed (Memeti et al, 2012).

\section{Principles of mental health law in the Former Yugoslav Republic of Macedonia}

In cases where there is a risk of imminent and high likelihood that a patient with a mental disorder will harm themselves, others and/or the surroundings (aggressive or suicidal behaviour etc.) and the patient is not willing to accept the treatment or is not in a position to understand the need for treatment, the patient can be subject to involuntary or non-consensual assessment and treatment.

In the FYR of Macedonia there is a clear legal process in accordance with international standards that regulates detention and medical treatment without the patient's consent, as set out in the provisions from paragraph 1 of article 59 in the Non-Litigation Law (2008). In summary, the main criteria for detention and treatment are the presence of mental illness and self-harm or harm to others.

Further, the grounds for non-consenting treatment are regulated through Chapter 2 of the Non-Litigation Law (Law on the Protection of Patients' Rights, 2008) whereby assessment, treatment and detention of involuntary patients is prescribed by the court and the procedure is urgent.

In article 58, detention in public health organisations is for the treatment of mental diseases. The court decides when the person with mental illness should be deprived the rights of freedom of movement and contact with the surrounding environment.

When a mental health organisation intends to treat a person with mental illness without their consent or without a court order, the public health organisation is obliged to inform the regional court within $48 \mathrm{~h}$. The court is obliged to appoint two independent doctors - one of them specialised in psychiatry - to conduct an independent assessment in the institution in which the treatment is provided. Following the medical examination and once an opinion has been provided, the Court is obliged to examine the circumstances and deliver a decision within the next $72 \mathrm{~h}$. 


\section{Discussion}

The post-independence law reforms in FYR of Macedonia provide substantial and procedural protection for the rights of patients with mental disorders, and they are in line with international best practice. The FYR of Macedonia has had a Mental Health Policy (Law on Mental Health, 2006) and mental health legislation since 2005. There is a national human rights review body that performs regular inspections and reviews complaints processes. However, there is a disparity between the law and its implementation in practice which is mainly due to an unjustified delay in legislating compulsory hospitalisation. The provisions from paragraph 2 of article 59 in the Non-Litigation Law (2008) are not fully implemented. More specifically, in everyday practice there are difficulties in procuring two adult witnesses who would fulfil the legally binding preconditions. In summary, the huge delays in legislating forced detention in FYR of Macedonia stems from the lack of collaboration between the court and the mental health institutions.

\section{References}

Apostolska Z., Tozija F. (2009) In cooperation with Lozanoska J. Analytical Support on the Socio-Economic Impact of Social Protection Reforms (ASISP) Annual report 2009 on Former Yugoslav Republic of Macedonia. Former Yugoslav Republic of Macedonia.

Law on Amendment and Addenda to the Law on the Protection of Patients' Rights (2011) Official Gazette of the Former Yugoslav Republic of Macedonia, No. 53/11, Article 5.

Law on Mental Health (2006) Official Gazette of the Former Yugoslav Republic of Macedonia, No. 71/06.

Law on the Protection of Patients' rights (2008) Official Gazette of the Former Yugoslav Republic of Macedonia, No.82/08.

Memeti I., Tomsik Stojkovska A., Boskovski D., et al (2012) Annual Report 2012-National Preventive Mechanism. Ombudsman of the Former Yugoslav Republic of Macedonia, pp. 213-308.

Non-Litigation Law (2008) Official Gazette of the Former Yugoslav Republic of Macedonia, No. 9/08.

World Health Organization (WHO) (2009) WHO-AIMS Report on Mental Health System in the Former Yugoslav Republic of Macedonia, World Health Organization.

\title{
EDITORIAL
}

\section{The mental health of asylum seekers in Australia and the role of psychiatrists}

\author{
Derrick Silove ${ }^{1}$ and Sarah Mares ${ }^{2,3}$
}

${ }^{1}$ Scientia Professor, School of Psychiatry, University of New South Wales, Sydney, Australia

${ }^{2}$ Conjoint Senior Lecturer, School of Psychiatry, University of New South Wales, Sydney, Australia. South Wales, Sydney, Australia.

Email s.mares@unsw.edu.a

University, Adelaide, Australia

Conflicts of interest. None.

Keywords. Ethics; human rights; immigration detention; mental health; asylum seekers and refugees; psychiatry.

\section{doi:10.1192/bji.2018.11}

(c) The Authors 2018. This is an Open Access article, distributed under the terms of the Creative Commons Attribution licence (http://creativecommons.org/ licenses/by/4.0/), which permits unrestricted re-use, distribution, and reproduction in any medion, and reproduction in any medium, provided the original work is properly cited.
There are more displaced people around the world than ever before, and over half are children. Australia and other wealthy nations have implemented increasingly harsh policies, justified as 'humane deterrence', and aimed at preventing asylum seekers (persons without preestablished resettlement visas) from entering their borders and gaining protection. Australian psychiatrists and other health professionals have documented the impact of these harsh policies since their inception. Their experience in identifying and challenging the effects of these policies on the mental health of asylum seekers may prove instructive to others facing similar issues. In outlining the Australian experience, we draw selectively on personal experience, research, witness account issues, reports by human rights organisations, clinical observations and commentaries. Australia's harsh response to asylum seekers, including indefinite mandatory detention and denial of permanent protection for those found to be refugees, starkly demonstrates the ineluctable intersection of mental health, human rights, ethics and social policy, a complexity that the profession is uniquely positioned to understand and hence reflect back to government and the wider society.

The Office of the United Nations High Commissioner for Refugees estimates the global number of refugees to stand at an unprecedented 65.3 million, with $50 \%$ being children (UNHCR, 2017). Most receive sanctuary in neighbouring countries, a small percentage reaching North America, Europe and Australasia. Despite this, Australia and other wealthy nations have implemented increasingly harsh policies of so-called 'humane deterrence', aimed at preventing asylum seekers (persons without preestablished resettlement visas) from entering their borders.

The experiences of Australian psychiatrists and allied health professionals in confronting the mental health effects of these policies on asylum seekers may prove instructive to colleagues in other countries facing similar issues. In outlining the Australian experience, we draw selectively on personal experience, research, witness accounts, reports by human rights organisations, clinical observations and commentaries. 